\title{
Effect of age on progesterone receptor expression, and osteoprogenitor proliferation and differentiation in female rat vertebral cell populations
}

\author{
Weidong Pei, Carlton G Bellows, Yongheng Jia and Johan N M Heersche \\ Faculty of Dentistry, University of Toronto, 124 Edward Street, Toronto, Ontario M5G 1G6, Canada \\ (Requests for offprints should be addressed to W Pei; Email: w.pei@utoronto.ca)
}

\begin{abstract}
In the present investigation, we evaluated whether the capacity for proliferation and differentiation of progesterone (Prog)dependent osteoprogenitors in the female rat skeleton is related to the level of Prog receptors (PRs) and/or the level of circulating estrogen. We confirmed that in rats, estrogen levels at 18 months of age are higher than those at 3 months, and higher again in rats of $22 \cdot 5,25 \cdot 5$, and 26 months of age. Prog levels in rats of ages between 18 and $25 \cdot 5$ months were lower than those at 26 and 3 months of age. PR-A levels were tenfold higher than those of PR-B in cell populations where PR-B was detectable; PR-B receptors were not detectable in all cell populations. In populations derived from $22 \cdot 5$ to 26 months old rats, the basal levels of PR-A were higher than those derived from 3 and 18 months old rats by five- and twofold respectively. Prog treatment enhanced PR-A expression in animals of all ages. Estrogen enhanced the effect of Prog on
\end{abstract}

PR-A expression in cell populations from the 3 and 18 months old rats, but had no effect on PR-A expression in cell populations from $22 \cdot 5,25 \cdot 5$, and 26 months old rats. This might be related to the high basal expression of PR in $22 \cdot 5-26$ months old rats (the 'persistent estrous' phase). Our results also confirm our previous observation that in rats, the number of Prog- and dexamethasone (Dex)- dependent osteoprogenitors, and the effect of estrogen on the response to Prog do not decrease with age. In conclusion, we have shown that the basal level of PR-A was increased in old rats, and that this correlated with increased serum estrogen levels, but not with the number of detectable Prog-dependent osteoprogenitors. We also found that Prog upregulates the expression of its own receptors and that estrogen enhances this in young rats but not in rats over 22.5 months of age, in which estrogen levels are elevated.

Journal of Endocrinology (2006) 190, 261-270

\section{Introduction}

We have shown previously that progesterone (Prog) stimulates proliferation and differentiation of osteoprogenitor cells in bone cell populations derived from adult female rats, but not in male rats (Ishida \& Heersche 1997, 1999), and that estrogen increased the number of Prog-dependent osteoprogenitors but had no effect on the dexamethasone (Dex)-dependent osteoprogenitors. In aging humans, osteoblast activity decreases. The question is whether this could be related to a selective effect of estrogen and/or Prog deficiency on Progdependent osteoprogenitors. To evaluate whether female sex steroids would selectively affect Prog-dependent osteoprogenitors, we ovariectomized 6 months old rats and determined the effects on various progenitors. We found that ovariectomy (OVX) of 6 months old rats led to a similar decrease in the number of colony forming units-fibroblast (CFU-F), alkaline phosphatase (AP)-positive CFU-F and Dex- and Prog-dependent osteoprogenitors in bone cell populations derived from these rats (Pei et al. 2003). Thus, no selective effect of OVX on Prog-dependent osteoprogenitors was seen. We further investigated a possible correlation between sex-steroid levels and Prog-dependent osteoprogenitors in aging rats with high estrogen levels (Chakraborty \& Gore 2004). Again, no correlation was found between Prog-dependent osteoprogenitors and serum estrogen levels (Bellows et al. 2003).

Estrogen and Prog have been shown to stimulate growth of human osteoblast-like cells and to increase AP activity in human bone derived cell cultures (Scheven et al. 1992, Verhaar et al. 1994). Prog (0·1-1000 nM) stimulated human osteoblast proliferation in a dose-dependent manner (Liang et al. 2003). In the human fetal osteoblastic cell line hFOB $1 \cdot 19$, transfected with the human estrogen receptor (ER) gene, Prog receptors (PRs) are upregulated by estrogen (Harris et al. 1995). More recently, Rickard et al. (2002) demonstrated that in human fetal osteoblast cell lines, stably transfected with either ER- $\alpha$ or ER- $\beta$, estrogen stimulated endogenous gene expression of both the PR-A and PR-B isoforms with ER- $\alpha$ as the predominant inducer.

The aim of the present investigation was to investigate whether the number of PRs in osteoprogenitors in female rats would change with increasing age, which in rats is associated with increased circulating estrogen levels. 


\section{Materials and Methods}

\section{Animals, tissue dissection, and serum collection}

Three-months old female Wistar rats (retired breeders, $n=10$ ) were obtained from Charles River Laboratories (St Constant, Canada), caged individually and allowed to age. A young rat (3 months old) and older rats (17, 18, 20, $22 \cdot 5,25 \cdot 5$, and 26 months) were euthanized (one per time point) by cervical dislocation. Prior to euthanization, blood samples were collected from the aorta under halothane anesthesia and the serum was separated by centrifugation and stored at $-80^{\circ} \mathrm{C}$ until assayed (Lu et al. 1979). Three other rats intended to be part of the experiments died between 20 and 26 months of age because of the development of tumors and were not included in the experiments. The research protocols were approved by the University of Toronto's Animal Research Review Committee.

\section{Culture and assay procedures}

The cell isolation procedure used allows for the reproducible isolation of osteoprogenitor cell populations from adult rat bone (Ishida \& Heersche 1997, 1999). Lumbar vertebrae (L1-L6) were collected and the cancellous bone from the vertebral bodies was aseptically dissected in PBS at $4{ }^{\circ} \mathrm{C}$ and cut into $\sim 1 \mathrm{~mm}^{3}$ fragments. The fragments (explants) were placed in plasma clots $(10 \mu \mathrm{l}$ of $15 \%$ citrated bovine plasma and $85 \% \alpha$-minimal essential medium ( $\alpha$-MEM) containing $20 \%$ fetal bovine serum (FBS) and antibiotics) with approximately 20 explants $/ 60 \mathrm{~mm}$ dish. After clotting $\left(\sim 1.5 \mathrm{~h}\right.$ at $37^{\circ} \mathrm{C}, 5 \% \mathrm{CO}_{2}$ in humidified air), medium containing 10\% FBS and antibiotics was added and culture continued. After 10-12 days of culture, cells in the outgrowths were detached by treatment with a $1: 1(\mathrm{v} / \mathrm{v})$ mixture of $0.03 \%$ collagenase (Sigma) and $0 \cdot 125 \%$ trypsin $(15 \mathrm{~min}$ at $\left.37^{\circ} \mathrm{C}\right)$. Cells were counted using a Coulter Counter (Beckman Coulter Electronics, Burlington, Canada) and plated at $10^{5}$ cells per $35 \mathrm{~mm}$ dish (1st subculture), and at $3 \times$ $10^{5}$ cells per $60 \mathrm{~mm}$ dish to initiate experiments for nodule events and receptor protein analysis, respectively. To determine the number of viable cells plated, the cells in three dishes of each experiment were detached after $24 \mathrm{~h}$ of culture by treatment with $0.05 \%$ trypsin and counted. The viability was determined by evaluating the percentage of viable cells relating to the number of cells originally plated. Cultures were grown for 19-22 days to permit development and mineralization of the nodules under control conditions and in the presence of Dex (10 $\mathrm{nM}$; Sigma), Prog $(3 \mu \mathrm{M}$; Calbiochem, San Diego, CA, USA), estrogen (17 $\beta$-estradiol, $10 \mathrm{nM}$; Calbiochem), and Prog plus estrogen as described previously (Ishida \& Heersche 1997, 1999). Sodium $\beta$-glycerophosphate $(\beta-\mathrm{GP}, 5 \mathrm{mM})$ was added during the final 4-7 days of the 19-22 day culture period to induce mineralization of osteoid nodules.
Staining procedures and nodule quantitation

Live cultures were examined daily using phase-contrast microscopy. To stain for AP activity, the cell layer was fixed in neutral buffered formalin for $15 \mathrm{~min}$, washed with distilled water, and then incubated for $45 \mathrm{~min}$ at room temperature with Tris- $\mathrm{HCl}$ buffer $(0 \cdot 1 \mathrm{M}, \mathrm{pH} 8 \cdot 3)$ containing naphthol AS-MX phosphate dissolved in N,N-dimethylformamide, and Fast Red Violet LB salt (Sigma) (Bellows et al. 2003). AP-stained cultures were subsequently stained with the von Kossa technique to identify mineralized bone nodules as previously described (Bellows et al. 2003). The number of bone nodules was counted using a dissecting microscope at $\times 13$ against a grid ruled in $2 \mathrm{~mm}$ squares prepared on an acetate sheet. It was established previously, by limiting dilution assays, that each of the AP-positive and von Kossa positive colonies (bone nodules) is derived from a single progenitor cell (Bellows \& Aubin 1989).

\section{Estradiol and progesterone RIA}

The serum was thawed at room temperature and three $1 \mathrm{ml}$ samples were tested separately using the RIAS described by Johnson et al. (1993) for estradiol, and by Hilborn \& Krahn (1987) for progesterone. The RIAS for estradiol and progesterone were analyzed using the Elecsys 1010/2010 System (Roche Diagnostics Corporation, Indianapolis, IN, USA) and the Immulite Analyser 2000 (Diagnostic Products Corporation, Los Angeles, CA, USA) respectively.

\section{Immunohistochemical procedure for detection of PRs}

Immunohistochemical staining, using the amplification procedure of Sternberger (1979), was carried out as described by Lessey et al. (1991). Cultures in $35 \mathrm{~mm}$ dishes were fixed in $3.7 \%$ formaldehyde in PBS at room temperature for $10 \mathrm{~min}$ and then immersed in $100 \%$ methanol at $4{ }^{\circ} \mathrm{C}$ for $4 \mathrm{~min}$. Before staining, cells were dehydrated through a series of 70 , 90 , and $100 \%$ ethanol, and endogenous peroxidase was blocked by incubating the cultures with $3 \%$ hydrogen peroxide for $5 \mathrm{~min}$ at room temperature. The cells were then incubated with the mouse monoclonal anti-rat PR antibody $\mathrm{AB}-7$ (NeoMarkers, Fremont, CA, USA) for $60 \mathrm{~min}$, followed by an incubation of $60 \mathrm{~min}$ with horseradish peroxidase-conjugated goat anti-mouse antibody (Kierkegaard \& Perry Laboratory Inc., Gaithersburg, MD, USA). Finally, the culture was incubated in a Vectastain $A B C$ reagent (peroxidase substrate solution, Vector Laboratories Inc., Burlingame, CA, USA) until staining in nodules was clearly visible.

\section{Preparation of whole cell extracts and protein determination}

At day 20 of culture, the cells were released from six dishes with $\boldsymbol{\alpha}$-MEM containing $1 \mathrm{mM}$ EDTA (Sigma). Remaining cells were scraped loose using a rubber scraper, and the dishes were rinsed with $\alpha$-MEM. The cells from two dishes were 
pooled, pelleted, and cell pellets were homogenized by passing through a 25 gage needle 20 times in $250 \mu \mathrm{l}$ extraction buffer $(50 \mathrm{mM}$ Tris-HCl, $7 \cdot 5 \mathrm{mM}$ EDTA, $10 \%$ glycerol, $0.6 \mathrm{M} \mathrm{NaCl}, \mathrm{pH} 7 \cdot 4)$ containing protease inhibitors $(1 \mathrm{mg} / \mathrm{ml}$ soybean trypsin inhibitor, $1 \mathrm{mM}$ phenylmethysulfonylfluoride, $0 \cdot 1 \mathrm{mg} / \mathrm{ml}$ leupeptin, $20 \mathrm{mM}$ sodium molybdate) on ice. Thus, six culture dishes yielded three different samples (one sample from two culture dishes). After each extract was transferred to an ultracentrifuge tube, $250 \mu \mathrm{l}$ of $5 \times$ Tris-EDTA-glycerol (TEG) buffer $(50 \mathrm{mM}$ Tris-HCl, $7 \cdot 5 \mathrm{mM}$ EDTA, $10 \%$ glycerol, $\mathrm{pH} 7 \cdot 4$ ) were added. Extracts were centrifuged at $130000 \mathrm{~g}$ for $25 \mathrm{~min}$. Aliquots of supernatants from each extract containing extracted PR were used for protein determinations using a Bio-Rad protein assay kit (Bio-Rad) and for immunoblot analysis to determine PR content.

\section{Immunoblot procedure for detection and quantitation of $P R$}

Whole cell extracts, obtained as described above, were combined with $1 / 3$ volume of sample buffer $(0 \cdot 25 \mathrm{M}$ Tris$\mathrm{HCl}, 8 \%$ SDS, $40 \%$ glycerol, $15 \% \quad \beta$-mercaptoethanol, bromophenol blue, $\mathrm{pH} 6 \cdot 8$ ), boiled at $100{ }^{\circ} \mathrm{C}$ for $10 \mathrm{~min}$ and frozen at $-80^{\circ} \mathrm{C}$ until analyzed by SDS-PAGE. Whole cell extracts of the human breast cancer cell lines MDA-231 and T47D were prepared in the same manner and used as negative and positive controls for PR respectively (Read et al. 1988).

Proteins were separated according to molecular weight in an $8 \%$ acrylamide denaturing/reducing gel using the method of Laemmli (1970). Samples were then transferred from the gel to nitrocellulose as described by Towbin et al. (1979), Greene et al . (1988) and Aronica et al. (1991). Samples on the nitrocellulose membranes were analyzed for PR content using mouse monoclonal anti-rat PR antibodies (PR AB-7 or PR AB-8, NeoMarkers, Fremont, CA, USA) followed by a horseradish peroxidase-conjugated goat anti-mouse antibody. Both antirat $\mathrm{PR}$ antibodies $\mathrm{PR} A B-7$ and $\mathrm{PR}$ AB-8 were used to detect PR-A and PR-B in T47D cell lines and rat cells, since both antibodies cross react with both human and rat PR-A and PR-B. PR AB-7 was used to analyze PR-A and PR-B levels in the rat cell cultures because of its slightly better reaction with PR-B. The immune complexes were then visualized and recorded by the Syngene program (Fisher Scientific Limited, Ottawa, Canada) with different exposure times. The membranes were then washed three times with washing buffer and stored at $4{ }^{\circ} \mathrm{C}$ until re-probed with glyceraldehyde-3phosphate dehydrogenase (GAPDH) antibody at the next day.

Three independent immunoblots were analyzed for each sample. In each experiment, the ratio of PR-A to GAPDH under control conditions was assigned a value of 1 . The effects of Dex (10 nM), Prog (3 $\mu \mathrm{M})$, estrogen (10 nM), and Prog $(3 \mu \mathrm{M})$ plus estrogen $(10 \mathrm{nM})$ on PR-A expression levels were expressed as the ratio of PR-A to GAPDH under each condition divided by the ratio of PR-A to GAPDH under control conditions. Since PR-B was not consistently present in all conditions, it was not analyzed.

\section{Statistical analysis}

Data were analyzed by unpaired two-tailed Student's $t$-test and linear regression using either Microsoft Excel or Graphpad Instat. All results are expressed as the mean and 95\% confidence interval (CI). Differences between different treatment groups within each animal were analyzed by unpaired two-tailed Student's $t$-test. Differences for each treatment group between young and old rats were analyzed by linear regression using Graphpad Instat. $P$ values $\leq 0.05$ were considered statistically significant.

\section{Results}

Effect of age on the number of Dex- and Prog-dependent osteoprogenitors

The effects of Dex, Prog, estrogen, and Prog plus estrogen on bone nodule formation in 1st subcultures of vertebral cells from $3,17,18,20,22 \cdot 5,25 \cdot 5$, and 26 months old female rats are shown in Fig. 1. The concentrations of Dex $(10 \mathrm{nM})$, $\operatorname{Prog}(3 \mu \mathrm{M})$, estrogen $(10 \mathrm{nM})$ and Prog plus estrogen used in this investigation were based on our previous findings indicating that in this system these concentrations had reproducible and significant effects (Ishida \& Heersche 1997, 1999, Bellows et al. 2003). Dex increased nodule formation to the same extent in cell populations from all ages. The response to Prog was lower, but also the same at all ages (Fig. 1A). Estrogen alone did not affect nodule formation in any of the populations, but potentiated the response to Prog in all cell populations (Fig. 1B). For all cell populations, the numbers of nodules per culture ranged from 370 to 520 in the presence of Dex and from 50 to 70 in the presence of Prog. The numbers of nodules in the presence of both estrogen and Prog were between 70 and 100 . These results essentially confirm results of our previous study (Bellows et al. 2003).

\section{Changes in circulating levels of estradiol and progesterone in rats of} different ages

To be able to compare PR levels in cell populations derived from rats of different ages with circulating levels of ovarian hormones, we measured serum levels of estradiol and progesterone in these rats. In the 3 months old cycling female rat, serum levels of estradiol were low, below the limit of detection for this assay $(50 \mathrm{pM})$. In the 18 months old rat, the estradiol level was $90 \mathrm{pM}$, while in the older rats $(22 \cdot 5,25 \cdot 5$, and 26 months), estradiol levels were almost twice as high as in the 18 months old rat (Fig. 2A). The Prog level in the 3 months old rat was around $100 \mathrm{nM}$, and this level dropped to $40 \mathrm{nM}$ in the 18 months old rat. Prog levels in the 22.5 and $25 \cdot 5$ months old rats were similar to those of the 18 months old rat, but the level of Prog in the 26 months old rat almost tripled compared to the levels in the 18-25.5 months old rats (Fig. 2B). 

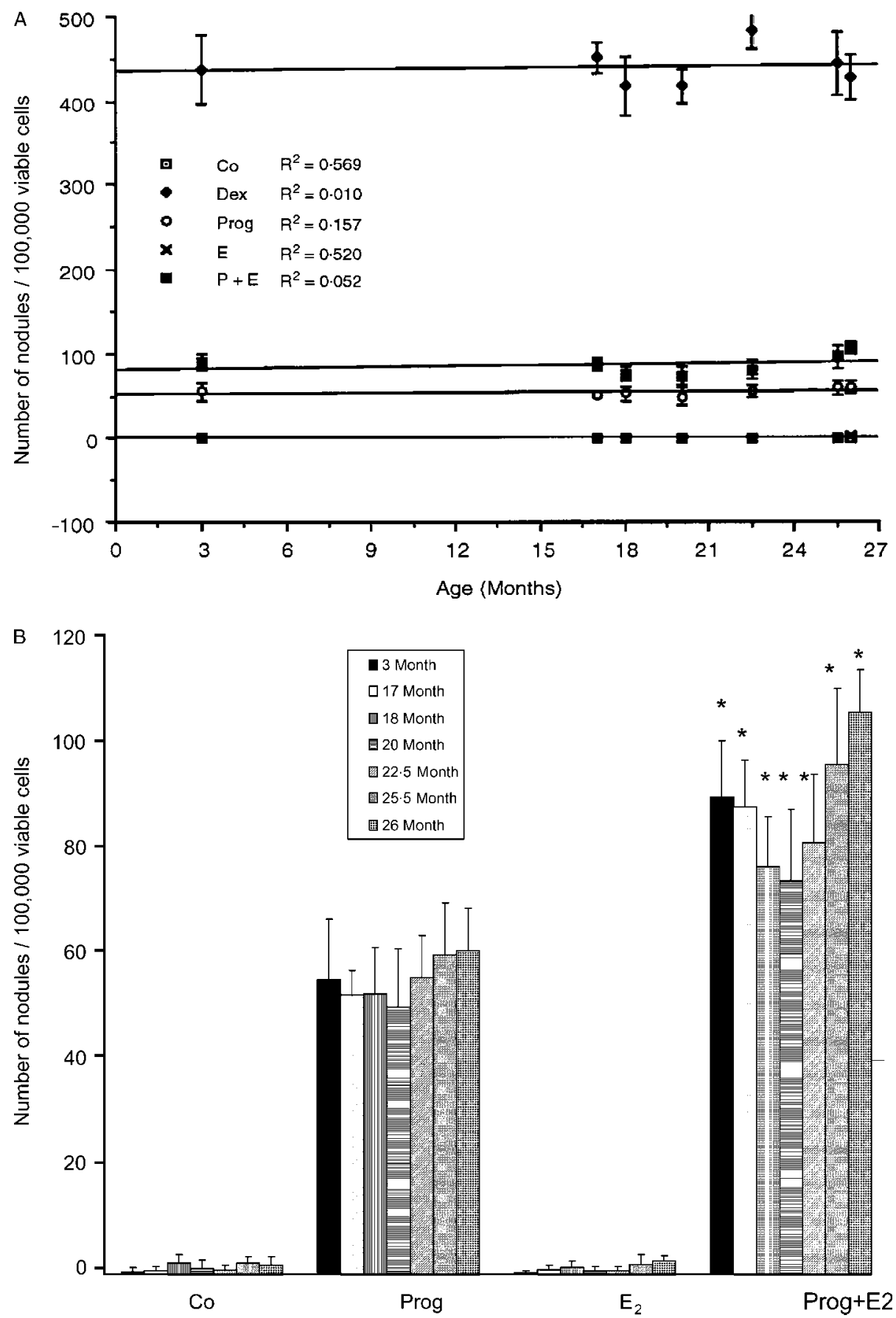

Figure 1 (A) The effect of Dex $(10 \mathrm{nM})$, Prog $(3 \mu \mathrm{M})$, estrogen $(10 \mathrm{nM})$ and Prog $(3 \mu \mathrm{M})$ plus estrogen $(10 \mathrm{nM})$ on nodule formation in cell populations derived from vertebrae of female rats at ages of $3,17,18$, $20,22 \cdot 5,25 \cdot 5$, and 26 months. Cells were plated at $10^{5}$ cells per $35 \mathrm{~mm}$ dish and cultured for 1922 days. Points represent the mean $\pm 95 \% \mathrm{Cl}$ of five cultures derived from the same animal. No significant difference in number of bone nodules was found between the different age groups under control conditions or in the presence of Dex, Prog, estrogen, and Prog plus estrogen. (B) The effect of estrogen on Prog-responsiveness on nodule formation in cell populations derived from vertebrae of female rats at ages of $3,17,18,20,22 \cdot 5,25 \cdot 5$, and 26 months. Cells were plated at $10^{5}$ cells per $35 \mathrm{~mm}$ dish and cultured for $19-22$ days. Results represent the mean $\pm 95 \% \mathrm{Cl}$ of five cultures. ${ }^{*}$, Significantly different from corresponding group treated with Prog only; $P<0 \cdot 05$. 

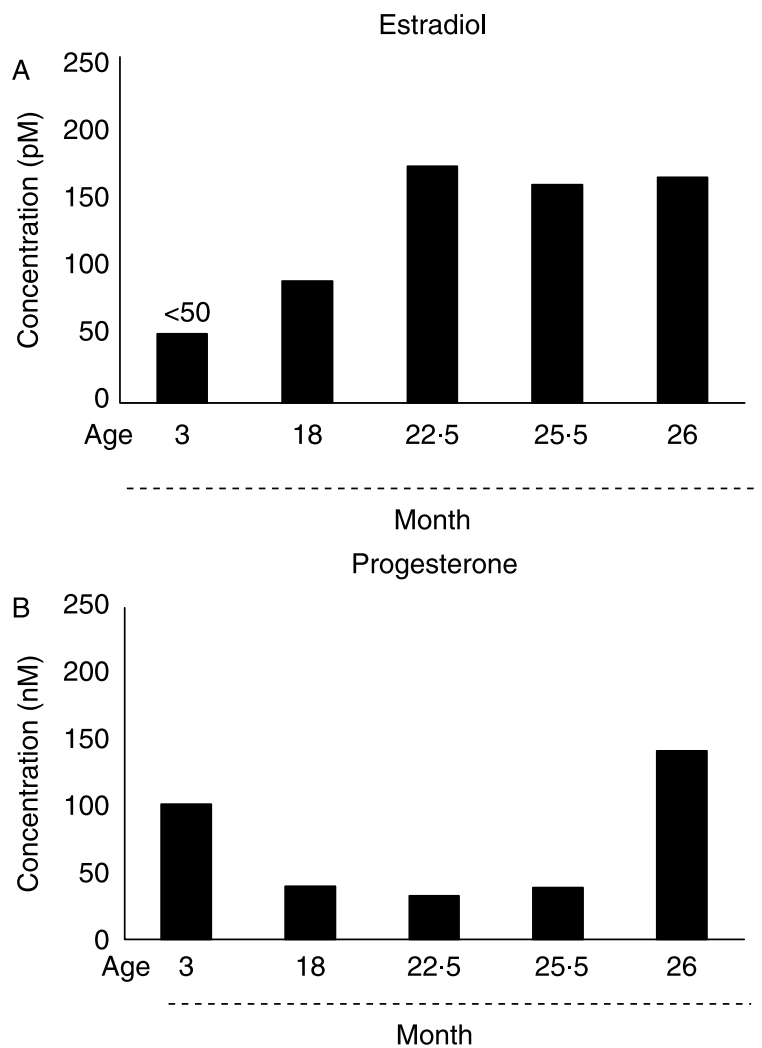

Figure 2 Serum concentration of estradiol $(\mathrm{pM})$ and progesterone $(\mathrm{nM})$ in rats of $3,18,22 \cdot 5,25 \cdot 5$, and 26 months old. Results represent the mean of three replicate measurements from the same sample.

PRs present under various culture conditions in cell populations derived from rats of different ages

To relate the effects of Prog on nodule formation to PR levels in the cell populations, we investigated both PR-A and PR-B levels. PR-A was consistently detectable under all culture conditions in all cell populations. However, PR-B was frequently not detectable. In the example shown in Fig. 3,

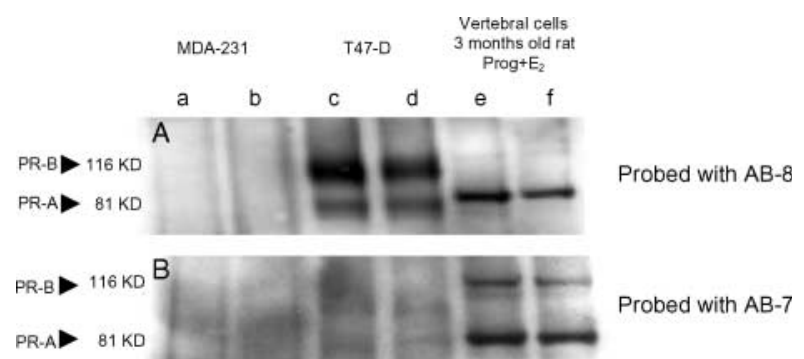

Figure 3 Immunoblot of PR-A and PR-B receptors in whole cell extracts of Prog plus estrogen-treated cultures derived from lumbar vertebrae of a 3-month old rat at day 20 of culture detected by antirat $P R$ antibody $A B-8$ (A: lane e and $f$ ) and $A B-7$ (B: lane e and $f$ ). Negative control; human breast carcinoma cell line MDA-231 (lane a and b). Positive control; human breast carcinoma cell line T47-D (lane $\mathrm{c}$ and $\mathrm{d}$ ). rat vertebral cell populations obtained from a 3-month old rat expressed both isoforms, with expression of PR-A much greater than that of PR-B ( $>$ tenfold). MDA-231 cells (human breast cancer cells) were used as a negative control, and T47-D cells (human breast cancer cells) as a positive control. Since, rat PR-A is roughly $1 \mathrm{kDa}$ larger than human PR-A, the position of rat PR-A is slightly higher than that of the human PR-A control.

We next analyzed the effects of Dex, Prog, and estrogen on PR-A expression at day 20 of culture as a function of age. Dex, Prog, and estrogen all increased the expression of PR-A in cell populations derived from the 3-month old rat by threeto fourfold (Fig. 4A). Populations treated with estrogen and Prog showed a higher level of PR-A expression than those treated with either estrogen or Prog alone. Since cultures treated with estrogen contain virtually no nodules (see Fig. 1), all PR detected in the estrogen-treated cultures must have been derived from non-nodule forming cells. Figure $4 \mathrm{~B}$ shows that in the cell population derived from the 18 months old rat, the effects of Dex, Prog, and estrogen on PR-A expression were essentially the same as those seen in the cell population derived from the 3 months old animal (Fig. 4A). However, the effects of Prog plus estrogen on PR-A appeared to be less than that observed in the 3-month old animal (Fig. 4A). Figure 5 shows the results obtained with the cell populations derived from the $22 \cdot 5,25 \cdot 5$, and 26 months old animals. The effects of Dex, Prog, and estrogen alone were similar to those obtained with cells from 3 and 18 months old animals. However, strikingly, the additive/synergistic effects of Prog plus estrogen observed in younger rats (3 and 18 months old) were absent in all three populations. In relation to this, it is of interest to note that under control conditions the expression of PR in cell populations derived from the $22 \cdot 5,25 \cdot 5$, and 26 months old rats was twice as high as the level in the population derived from the 18 months old rat and 4-5 times higher than that in the population derived from the 3 months old rat (Fig. 6).

\section{Detection of PR in nodule-containing cultures}

To evaluate the localization of PR in our cultures, we localized PR-containing cells immunohistochemically in nodulecontaining cultures. In a Prog-treated culture derived from a 3-month old rat, the highest levels of PR were expressed in active and differentiating osteoblasts located in the bone nodules, while the expression in the adjacent non-nodule forming cells was lower (Fig. 7A). Results for nodulecontaining Dex-treated cultures were similar (Fig. 7B).

\section{Discussion}

Prog and estrogen levels increase in rats over 18 months of age. The aim of the present study was to investigate whether the number of PRs in bone nodule-forming osteoblastic cell 
A 3 Month

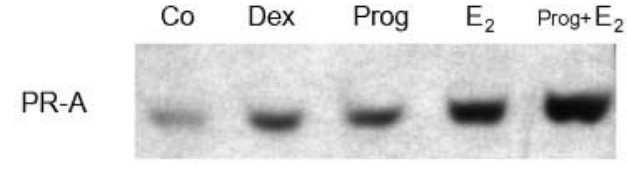

GAPDH
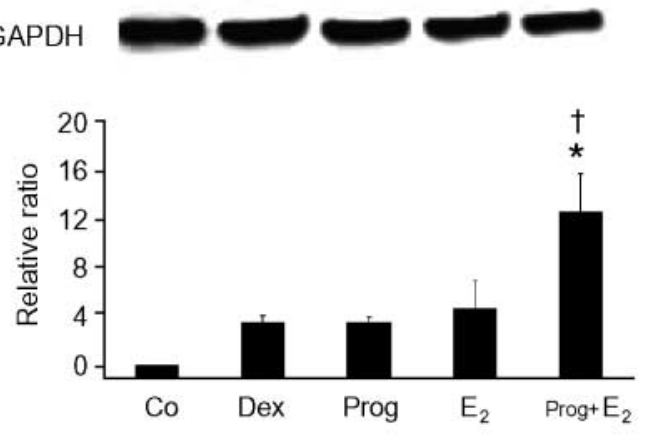

B

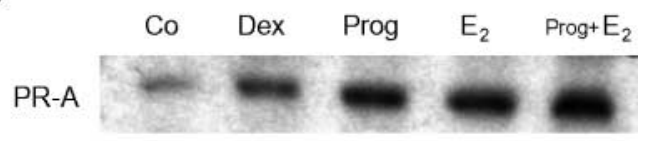

\section{GAPDH}
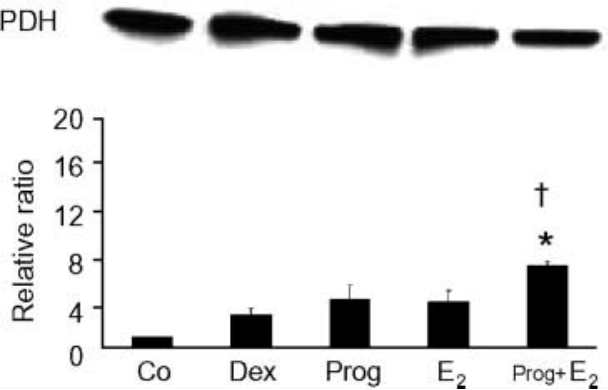

Figure 4 Immunoblot analysis of the expression of PR-A using antirat $\mathrm{PR}$ antibody $\mathrm{AB}-7$ in cell populations from lumbar vertebrae of 3 (Fig. 4A) and 18 (Fig. 4B) months old rats at day 20 under control (Co)-, Dex (10 nM)-, Prog $(3 \mu \mathrm{M})-, E_{2}(10 \mathrm{nM})-$, and Prog $(3 \mu \mathrm{M})+$ $\mathrm{E}_{2}(10 \mathrm{nM})$-treated conditions. The ratios of intensity of the PR-A band to the GAPDH band under control conditions was normalized to 1 , and the ratios of intensity of the PR-A band to the GAPDH in other culture conditions were expressed as a relative ratio (fold increase) to the ratio of intensity of PR-A band to GAPDH band under the control condition accordingly. Results represent the mean $\pm 95 \% \mathrm{Cl}$ of three independent experiments. *, Significantly different from corresponding group treated with Prog only; $t$, significantly different from corresponding group treated with estrogen only; $P<0 \cdot 05$.

populations would change with increasing age and the associated increase in circulating estrogen levels, or whether this number would remain the same, and correlate with the number of Prog- and Dex-dependent osteoprogenitors in these populations.

In agreement with our previous observation, we found that Dex- and Prog-dependent osteoprogenitors were both
A 22.5 Month

PR-A
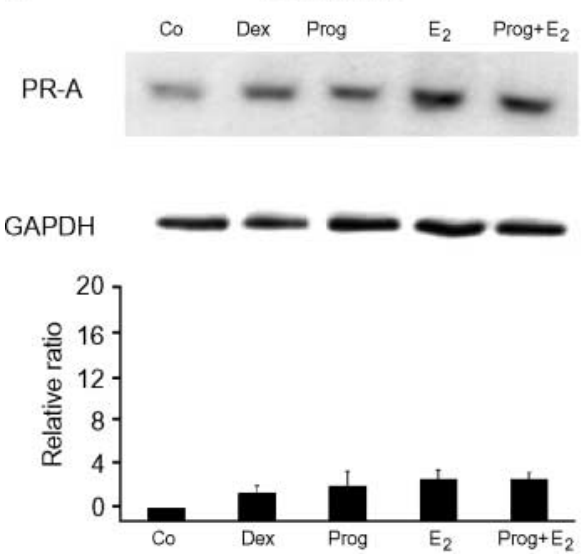

B

PR-A
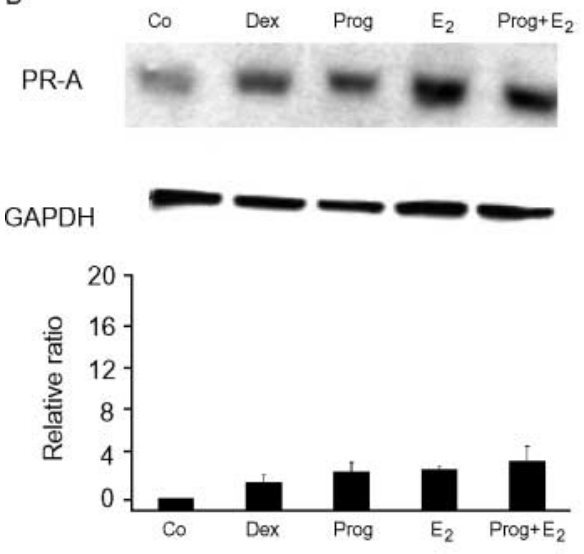

C
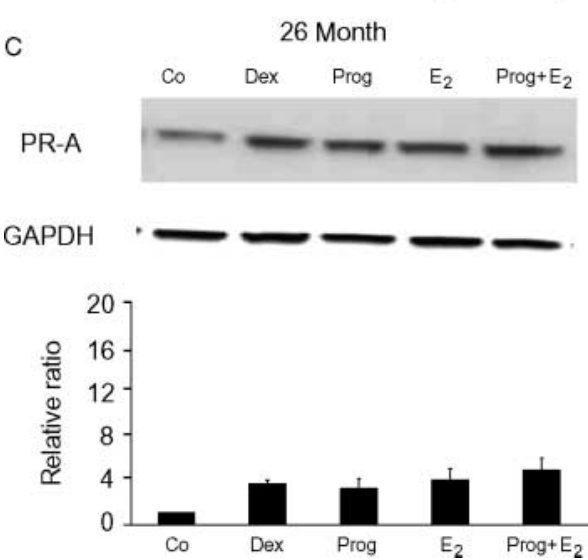

Figure 5 Immunoblot analysis of the expression of PR-A using antirat $\mathrm{PR}$ antibody $\mathrm{AB}-7$ in cell populations from lumbar vertebrae of (A) $22 \cdot 5$, (B) $25 \cdot 5$, and (C) 26 months old rats at day 20 under control (Co)-, Dex (10 nM)-, Prog $(3 \mu \mathrm{M})-, \mathrm{E}_{2}(10 \mathrm{nM})-$, and Prog $(3 \mu \mathrm{M})+\mathrm{E}_{2}(10 \mathrm{nM})$-treated conditions. The ratios of intensity of PR-A band to GAPDH band under the control condition was normalized to 1 , and the ratios of intensity of PR-A band to GAPDH in other conditions were expressed as a relative ratio (fold increase) to the ratio of intensity of PR-A band to GAPDH band under the control condition accordingly. Results represent the mean $\pm 95 \% \mathrm{CI}$ of three independent experiments. 


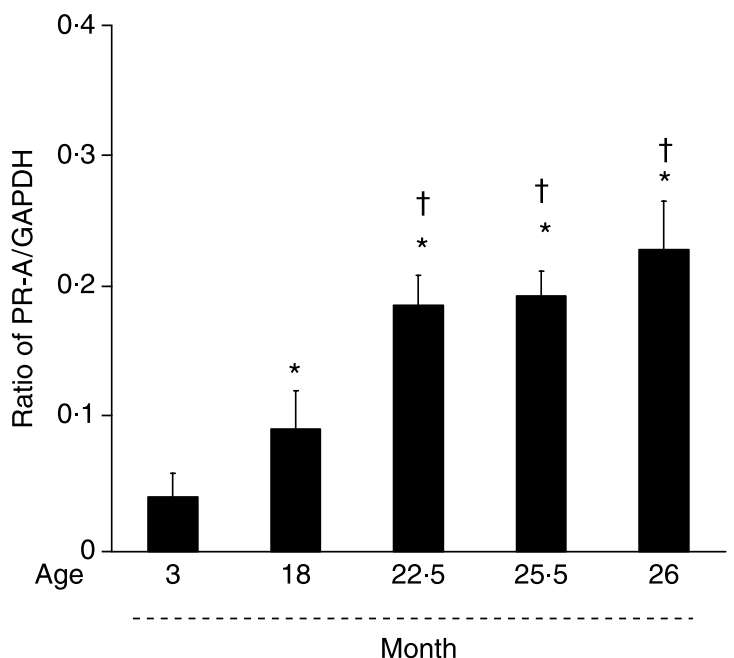

Figure 6 Immunoblot analysis of the expression of PR-A using antirat $\mathrm{PR}$ antibody $\mathrm{AB}-7$ in cell populations from lumbar vertebrae of 3 , $18,22 \cdot 5,25 \cdot 5$, and 26 months old rats at day 20 under control conditions. Results represent the mean $\pm 95 \% \mathrm{Cl}$ of three independent experiments. *, Significantly different from corresponding 3 months old rat; $\uparrow$, significantly different from corresponding 18 months old rat; $P<0 \cdot 05$.

present in cell populations derived from rats between 17 and 26 months age and that the numbers of both these two types of osteoprogenitors were not affected by age (Bellows et al. 2003). We also observed that with respect to bone nodule formation estrogen enhanced the Prog effect similarly in all populations. Sibonga et al. (2000) have reported recovery of bone loss in severely osteopenic senescent rats by treatment with prostaglandin $\mathrm{E}_{2}$ (PGE) for up to 2 months. This suggests that aging may not necessarily decrease the number of osteoprogenitor cells, but that a lack of PGE and not a lack of osteoprogenitors were responsible for the osteopenia (Sibonga et al. 2000, Cui et al. 2001, Zhou et al. 2001). This agrees with our observation.

We measured the levels of estradiol and progesterone in serum from young and old rats, and found that estrogen levels were higher in the 18 months old rat than in the 3 months old rat, and higher again in rats of $22 \cdot 5,25 \cdot 5$, and 26 months old. This agrees with the observations of Chakraborty \& Gore (2004). Interestingly, Prog levels in rats of ages between 18 and 25.5 months were lower than that in the 26 months old rat and the 3 months old rat. The levels of estradiol and progesterone that we found are comparable to those found by Huang \& Meitis (1975), Lu et al. (1979), LeFevre \& McClintock (1988).

In all the cell populations used in this study, we found that PR-A was readily detectable, while PR-B was not consistently detected. When both receptors were present, the ratio of PR-A to PR-B was greater than 10:1. Others have observed that in the rat PR-A expression in ovary, mammary glands, and uterus is also greater than that of PR-B (Schneider et al. 1991). With respect to the functions of PR-A and PR-B, the two receptors are considered to display distinct transactivational activities that are specific to both the cell type and the target gene promoters (Tora et al. 1988, Meyer et al. 1992, Vegeto et al. 1993, Hovland et al. 1998, Mulac-Jericevic and Conneely 2004). While PR-B can function as a very strong activator of $\mathrm{PR}$-dependent gene transcription in cell types, in which PR-A is inactive, PR-A can repress the activity of PR-B in cultures of cells, in which PR-A and PR-B are both expressed (Vegeto et al. 1993, Giangrande \& McDonnell 1999). Pieber et al. (2001) also reported that human PR-A inhibited the transcription initiated by human PR-B receptor activation. Graham \& Clarke $(1997,2002)$ postulated that PR-A might function as a repressor of PR-B. Furthermore, by using PR-A knockout mice, Mulac- Jericevic et al. (2000) showed that the PR-B mediated effects are completed abolished by PR-A mediated effects in terms of the estrogen-induced proliferation in the murine uterine epithelium. In our case, the predominance of PR-A is most likely to suppress the expression of $\mathrm{PR}-\mathrm{B}$ in the rat bone cell populations.

We found that Dex, Prog, and estrogen stimulated the expression of PR-A in cell populations derived from rats of all ages. The effects of Prog and estrogen appeared to be additive or synergistic in populations from the 3- and 18-month old rats, but not in cells obtained from $22 \cdot 5,25 \cdot 5$, and 26 -month old rats. Interestingly, estrogen did not stimulate nodule formation, but increased PR expression was observed in estrogen-treated cultures, suggesting that estrogen increased $\mathrm{PR}$ expression in non-nodule forming cells. The effects of Prog and estrogen on increasing PR expression observed by us here are compatible with the results of Slootweg et al. (1992), who showed that Prog and estrogen synergistically stimulated the proliferation of the human osteosarcoma cell line SaOS-2 and that this stimulation correlated with increased numbers of PRs and ERs in these cells. Similarly, the PR (and ER) content of the human uterus was shown to be increased with increasing Prog and estrogen levels during the proliferative phase of the menstrual cycle, and decreased during the luteal phase, paralleling the decrease in Prog and estrogen levels (Lessey et al. 1991). Estrogen has also been shown to enhance PR expression in human fetal osteoblast cell lines and to act via both ER isoforms (Rickard et al. 2002). In our experiments, the Prog- and estrogen-induced increased expression of the PR-A was similar in populations from all age groups. This is comparable to previous observations in the ventromedial nucleus, arcuate nucleus, and preoptic area of the brain of estrogen-treated ovariectomized rats where the effects of estrogen on PR were not affected by the age of the rats (Fubanashi et al. 2000). Our immunohistochemical evidence demonstrated that osteoblastic cells express more PR than non-nodule forming cells. We have also found that estrogen upregulates the number of PR-A receptors in non-nodule forming populations. The high basal levels of expression of PR in cells derived from rats with 22.5 months of age or older may have resulted from the higher circulating levels of estrogen in these animals. We suggest that the high basal levels of PR-A in those 

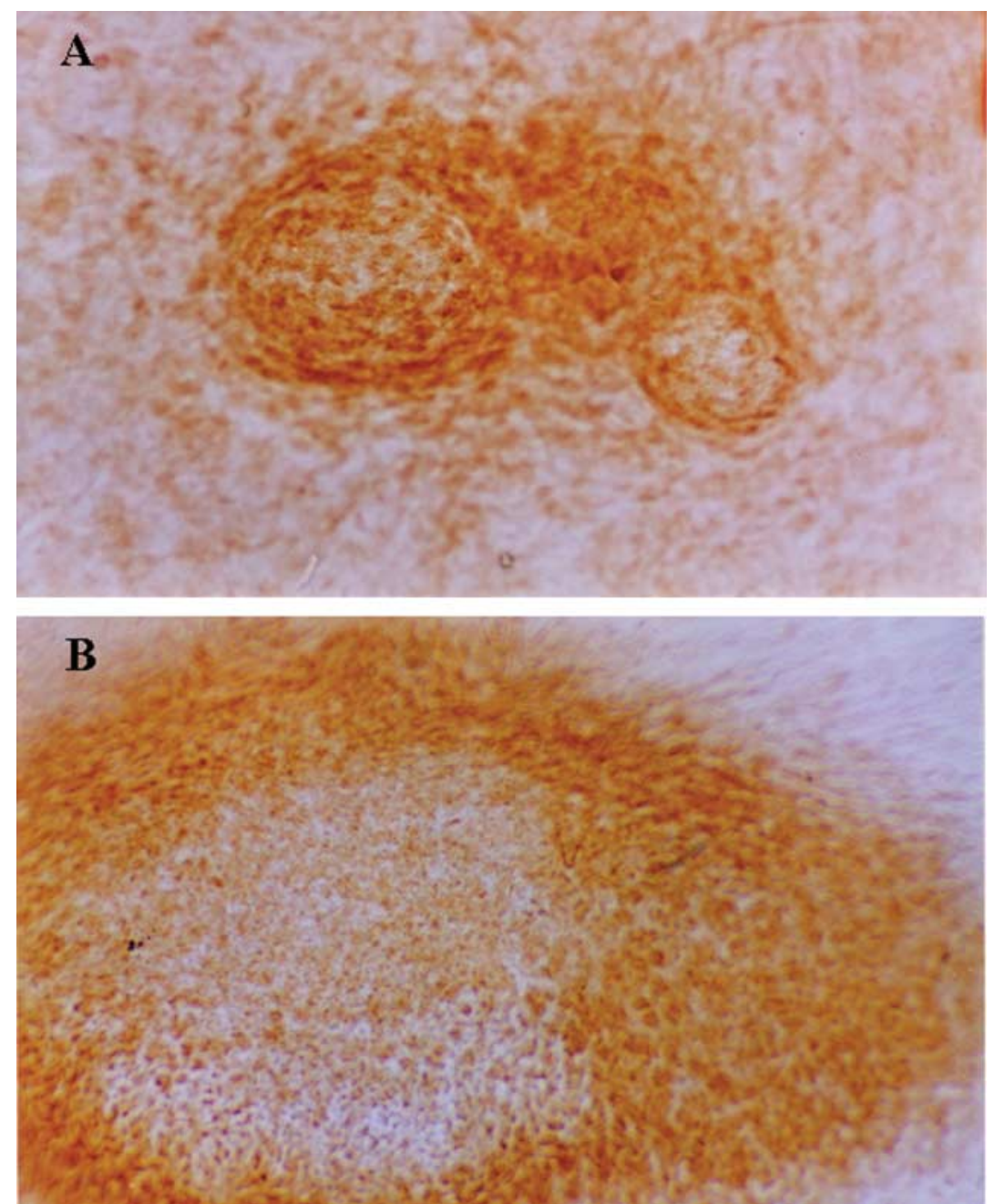

Figure 7 Immunohistochemical staining of PR using anti-rat $P R$ antibody $A B-7$ in a nodule and surrounding cells in a culture treated with Prog $(3 \mu \mathrm{M} ; \mathrm{A})$ and Dex $(10 \mathrm{nM}$; B) derived from lumbar vertebrae of 3 months old rats. Staining is concentrated in the nodule.

Magnification of A and B: $400 \times$.

cultures (two- to fourfold higher than in younger rats) may negatively affect the upregulation of PRs in the whole cell population. However, it is still possible that, while other cell types may not respond to the combination of Prog and estrogen, the osteoblastic cells in the populations still may respond. Since the osteoblastic cells comprise a relatively small proportion of the total cell population, this osteoblast-specific effect may not be detectable with the methods used. If the osteoblastic cells would have responded to the combination of estrogen and Prog with an increase in the number of PR (undetected), the persistence of the stimulatory effect of estrogen on Prog-induced nodule formation in cell populations derived from rats of 22.5 months or older could still be related to an increase in the number of PR-A.

The PR levels in cell populations derived from $22 \cdot 5$ to 26-month old rats were similar in cultures treated with estrogen, Prog and Prog plus estrogen. However, this was clearly different from results obtained with cell populations from the 3 and 18 month old rats where PR levels in cultures treated with both Prog and estrogen together were significantly higher than those in cultures treated with estrogen and Prog alone. This may be related to the changes in sex-steroid hormone levels we observed in the aging female rats. In our rats, the high levels of estradiol in the $22 \cdot 5-26$ months old group may have resulted in an increased expression of PR in all cell types, possibly to a level where no further increase in the number of receptors occurs following stimulation by either Prog or estrogen. The observed much higher baseline level of PR-A under control culture conditions in the $22 \cdot 5,25 \cdot 5$, and 26 months old rats when compared with the 3 and 18 months old rats supports this possibility. Relevant to this, Haywood et al. (1999) found 
that PR expression in rat brainstem norepinephrine neurons during the estrous cycle correlated with estrogen levels. In the anteroventral periventricular nucleus of the rat brain, ER $\alpha$ has also been reported to increase with age (Chakraborty \& Gore 2004).

In summary, we have shown that the basal level of PR-A was elevated in bone nodule forming osteoblastic cell populations derived from old rats, and this correlated with increased serum estrogen levels, but not with the number of detectable Prog-dependent osteoprogenitors. We also found that Prog upregulates the expression of its own receptors and this is enhanced by estrogen in young rats, but not in rats over 22.5 months of age, in which estrogen levels are elevated. The gradual adaptation from a short period of high levels of estrogen in regular cycling young rats, to a prolonged period of high levels of estrogen in irregular cycling rats $(\sim 18$ months), and finally to persistent high levels of estrogen in 'persistent estrus' rats (aged between 22.5 and 26 months), may have resulted in the gradual upregulation of PR-A levels and the disappearance of the effect of estrogen on Proginduced PR-A expression.

\section{Acknowledgements}

We would like to thank Dr Azar Azad for performing the RIA of serum concentration of estradiol and progesterone, Dr Reinhold Vieth for assistance with the statistical analysis, and Dr Morris Manolson for critical discussions throughout these studies. This work was supported by the CIHR grant MT14655. The authors declare that there is no conflict of interest that would prejudice the impartiality of this scientific work.

\section{References}

Aronica SM \& Katzenellenbogen BS 1991 Progesterone receptor regulation in uterine cells: stimulation by estrogen, cyclic adenosine $3^{\prime}, 5^{\prime}-$ monophosphate, and insulin-like growth factor I and suppression by antiestrogens and protein kinase inhibitors. Endocrinology 128 2045-2052.

Bellows CG \& Aubin JE 1989 Determination of numbers of osteoprogenitors present in isolated fetal rat calvaria cells in vitro. Developmental Biology 133 8-13.

Bellows CG, Pei W, Jia Y \& Heersche JNM 2003 Proliferation, differentiation and self-renewal of osteoprogenitors in vertebral cell populations from aged and young female rats. Mechanism of Ageing and Development 124 747-757.

Chakraborty TR \& Gore AC 2004 Aging-related changes in ovarian hormones, their receptors, and neuroendocrine function. Experimental Biology and Medicine 229 977-987.

Cui L, Ma YF, Yao W, Zhou H, Setterberg RB, Liang TC \& Jee WS 2001 Cancellous bone of aged rats maintains its capacity to respond vigorously to the anabolic effects of prostaglandin E2 by modeling-dependent bone gain. Journal of Bone and Mineral Metabolism 19 29-37.

Funabashi T, Kleopoulos SP, Brooks PJ, Kimura F, Pfaff DW, Shinohara K \& Mobbs CV 2000 Changes in estrogenic regulation of estrogen receptor alpha mRNA and progesterone receptor mRNA in the female rat hypothalamus during aging: an in situ hybridization study. Neuroscience Research 38 85-92.

Giangrande PH \& McDonnell DP 1999 The A and B isoforms of the human progesterone receptor: two functionally different transcription factors encoded by a single gene. Recent Progress of Hormone Research 54 291-313.
Graham JD \& Clarke CL 1997 Physiological action of progesterone in target tissues. Endocrine Review 18 502-519.

Graham JD \& Clarke CL 2002 Expression and transcriptional activity of progesterone receptor A and progesterone receptor B in mammalian cells. Breast Cancer Research 4 187-190.

Greene GL, Harris K, Bova R, Kinders R, Moore B \& Nolan C 1988 Purification of T47D human progesterone receptor and immunochemical characterization with monoclonal antibodies. Molecular Endocrinology 2 714-726.

Harris SA, Tau KR, Enger RJ, Toft DO, Riggs BL \& Spelsberg TC 1995 Estrogen response in the hFOB 1.19 human fetal osteoblastic cell line stably transfected with the human estrogen receptor gene. Journal of Cellular Biochemistry 59 193-201.

Haywood SA, Simonian SX, van der Beek EM, Bicknell RJ \& Herbison AE 1999 Fluctuating estrogen and progesterone receptor expression in brainstem norepinephrine neurons through the rat estrous cycle. Endocrinology 140 3255-3263.

Hilborn S \& Krahn J 1987 Effect of time of exposure of serum to gel-barrier tubes on results for progesterone and some other endocrine tests. Clinical Chemistry 33 203-204.

Hovland AR, Powell RL, Takimoto GS, Tung L \& Horwitz KB 1998 An $\mathrm{N}$-terminal inhibitory function, IF, suppresses transcription by the A-isoform but not the B-isoform of human progesterone receptors. Journal of Biological Chemistry 273 5455-5460.

Huang HH \& Meites J 1975 Reproductive capacity of aging female rats. Neuroendocrinology 17 289-295.

Ishida Y \& Heersche JN 1997 Progesterone stimulates proliferation and differentiation of osteoprogenitor cells in bone cell populations derived from adult female but not from adult male rats. Bone 20 17-25.

Ishida Y \& Heersche JNM 1999 Progesterone- and dexamethasonedependent osteoprogenitors in bone cell populations derived from rat vertebrae are different and distinct. Endocrinology 140 3210-3218.

Johnson MR, Carter G, Grint C \& Lightman SL 1993 Relationship between ovarian steroids, gonadotrophins and relaxin during the menstrual cycle. Acta Endocrinologica 129 121-125.

Laemmli UK 1970 Cleavage of structural proteins during the assembly of the head of bacteriophage T4. Nature 227 680-685.

LeFevre J \& McClintock MK 1988 Reproductive senescence in female rats: a longitudinal study of individual differences in estrous cycles and behavior. Biological Reproduction 38 780-789.

Lessey BA, Killam AP, Metzger DA, Haney AF, Greene GL \& McCarty KS, Jr. 1991 Immunohistochemical analysis of human uterine estrogen and progesterone receptors throughout the menstrual cycle. Journal of Clinical Endocrinology and Metabolism 67 334-440.

Liang M, Liao EY, Xu X, Luo XH \& Xiao XH 2003 Effects of progesterone and 18-methyl levonorgestrel on osteoblastic cells. Endocrine Research 29 483-501.

Lu KH, Hopper BR, Vargo TM \& Yen SS 1979 Chronological changes in sex steroid, gonadotropin and prolactin secretions in aging female rats displaying different reproductive states. Biological Reproduction 21 193-203.

Meyer ME, Quirin-Stricker C, Lerouge T, Bocquel MT \& Gronemeyer H 1992 A limiting factor mediates the differential activation of promoters by the human progesterone receptor isoforms. Journal of Biological Chemistry 267 10882-10887.

Mulac-Jericevic B \& Conneely OM 2004 Reproductive tissue selective actions of progesterone receptors. Reproductive tissue selective actions of progesterone receptors. Reproduction 128 139-146.

Mulac-Jericevic B, Mullinax RA, DeMayo FJ, Lydon JP \& Conneely OM 2000 Subgroup of reproductive functions of progesterone mediated by progesterone receptor-B isoform. Science 289 1751-1754.

Pei W, Bellows CG, Elsubeihi ES \& Heersche JN 2003 Effect of ovariectomy on dexamethasone- and progesterone-dependent osteoprogenitors in vertebral and femoral rat bone cell populations. Bone 33 822-830.

Pieber D, Allport VC \& Bennett PR 2001 Progesterone receptor isoform A inhibits isoform B-mediated transactivation in human amnion. European Journal of Pharmacology 427 7-11. 
Read LD, Snider CE, Miller JS, Greene GL \& Katzenellenbogen BS 1988 Ligand-modulated regulation of progesterone receptor messenger ribonucleic acid and protein in human breast cancer cell lines. Molecular Endocrinology 2 263-271.

Rickard DJ, Waters KM, Ruesink TJ, Khosla S, Katzenellenbogen JA, Katzenellenbogen BS, Riggs BL \& Spelsberg TC 2002 Estrogen receptor isoform-specific induction of progesterone receptors in human osteoblasts. Journal of Bone Mineral Research 17 580-592.

Scheven BA, Damen CA, Hamilton NJ, Verhaar HJ \& Duursma SA 1992 Stimulatory effects of estrogen and progesterone on proliferation and differentiation of normal human osteoblast-like cells in vitro. Biochemical and Biophysical Research Communications 186 54-60.

Schneider W, Ramachandran C, Satyaswaroop PG \& Shyamala G 1991 Murine progesterone receptor exists predominantly as the 83-kilodalton 'A' form. Journal of Steroid Biochemistry and Molecular Biology 38 285-291.

Sibonga JD, Zhang M, Ritman EL \& Turner RT 2000 Restoration of bone mass in the severely osteopenic senescent rat. Journals of Gerontology. Series A, Biological Sciences and Medical Sciences 55 B71-B84.

Slootweg MC, Ederveen AG, Schot LP, Schoonen WG \& Kloosterboer HJ 1992 Oestrogen and progesterone synergistically stimulate human and rat osteoblast proliferation. Journal of Endocrinology 133 R5-R8.

Sternberger LA 1979 Immunocytochemistry. In Immunocytochemistry, 2nd edn, p 104. Wiley, New York, NY, USA.
Tora L, Gronemeyer H, Turcotte B, Gaub MP \& Chambon P 1988 The $\mathrm{N}$-terminal region of the chicken progesterone receptor specifies target gene activation. Nature 333 185-188.

Towbin H, Staehelin T \& Gordon J 1979 Electrophoretic transfer of proteins from polyacrylamide gels to nitrocellulose sheets: procedure and some applications. Biotechnology 24 145-149.

Vegeto E, Shahbaz MM, Wen DX, Goldman ME, O'Malley BW \& McDonnell DP 1993 Human progesterone receptor A form is a cell- and promoter-specific repressor of human progesterone receptor B function. Molecular Endocrinology 7 1244-1255.

Verhaar HJ, Damen CA, Duursma SA \& Scheven BA 1994 A comparison of the action of progestins and estrogen on the growth and differentiation of normal adult human osteoblast-like cells in vitro. Bone 15 307-311.

Zhou S, Zilberman Y, Wassermann K, Bain SD, Sadovsky Y \& Gazit D 2001 Estrogen modulates estrogen receptor alpha and beta expression, osteogenic activity, and apoptosis in mesenchymal stem cells (MSCs) of osteoporotic mice. Journal of Cellular Biochemistry (Suppl 36) 144-155.

Received in final form 2 May 2006

Accepted 4 May 2006

Made available online as an Accepted Preprint

29 May 2006 